\title{
Differences in Partners' Perception and the Performance of German-Chinese Joint Ventures
}

\author{
Dr. David Rygl \\ Steinbeis University Berlin \\ School of International Business and Entrepreneurship \\ Albrecht-Dürer-Platz 4, D-90403 Nürnberg, Germany \\ Tel: 49-911-2427-7775 E-mail: rygl@steinbeis-sibe.de
}

Received: June 19, 2012

doi:10.5430/jbar.v1n1p86
Accepted: July 9, 2012

Online Published: July 10, 2012

URL: http://dx.doi.org/10.5430/jbar.v1n1p86

\begin{abstract}
This study discusses the role of differences in individuals' perception for research in international management in general, and then explores the extent to which partner firm representatives of German-Chinese Joint Ventures (GCJVs) differ in their perception of various characteristics of their co-operation. In a second step the article suggests how differences in partners' perceptions of key variables in the management of International Joint Ventures (IJVs) are associated with the perceived performance of such ventures. Using empirical data gathered from 38 General Managers and senior managers representing both sides of 19 GCJVs in the People's Republic of China (PRC), asymmetries in partners' perceptions and their association with the perceived performance of the IJV are explored empirically. The results show interesting differences in perception between the German and Chinese partners, and some significant relationships between the differences in perceptions and IJV performance.

The key results of the paper are that (1) there are considerable differences in the perceptions of managers representing the different sides of a JV, and (2) that these differences are related to differences in the perception of IJV performance. The paper contributes to research and practice by identifying and providing first empirical data on the magnitude of perceptual differences in IJVs and their potential relevance for the performance of IJVs.
\end{abstract}

Keywords: International Joint Ventures, partner perceptions, German-Chinese Joint Ventures

\section{Introduction}

Extant research in international business and management usually builds on realism as its ontological fundament and the assumption that there is a reality that is external to the individual and exists 'beyond the eye of the beholder'. The interest of researchers subscribing to this view is thus the 'objective reality'. A more subjectivist approach, on the other hand, assumes that reality does not exist detached from individual perception; rather, reality is seen as "the product of individual cognition" (Burrell \& Morgan, 1985: 1). Although the paper does not intend to venture deeper into this debate, it suggests that for many managerial problems it is the actions of individuals which are of interest, which in turn are based (among other things) on the reality the individuals perceive. Thus, the paper assumes that irrespective of an objectively existing reality it is the perception that leads an individual to act in a given way. Researchers in various disciplines have recognized the role of perceptions, and the fact that there are differences in individuals' perceptions that influence managerial decision-making (Wilson, Chen \& Erakovic, 2006). Perceptual differences have long been recognized as a particularly salient problem for (empirical) research spanning two or more cultures. The relevance of cultural differences in individuals' perception has been stressed with regard to the perception of women as managers (Owen \& Scherer, 2002), brands (Romaniuk \& Sharp, 2003), ethics and morals (Ahmed, Chung, \& Eichenseher, 2003, Elahee, Kirby, \& Nasif, 2002), risk (Weber \& Hsee, 1998), and productivity, job satisfaction, and leadership (Triandis 1982). There are (at least) two possible explanations for these differences: A possible explanation is that individuals perceive the analyzed issues to be different. If, for example, individuals from different cultures are asked about their satisfaction with a specific product, differences in scores may simply imply that the product does not meet the tastes in, or does not cater to the requirements of, one of the individuals/subcultures/cultures. An alternative explanation would be that the perception of the analysed issues is similar across cultures, but respondents from different cultures differ in their willingness to report their perception. 
For instance, certain cultures (e.g. Asian cultures) may be less inclined to use extreme points of a measurement scales. Measuring the satisfaction of a company's employees, suppliers, clients, etc., in different cultures thus raises the question as to the use of the resulting comparisons, as individuals belonging to a specific culture may report generally higher/lower scores than respondents from other cultures (Kittler, Rygl \& Mackinnon 2011). This means that low satisfaction scores may have to be attributed to cultural differences in the evaluation of satisfaction rather than to a low satisfaction of the individuals in question. Scholars have suggested various ways of dealing with this problem, such as, for example, normalizing responses using sub-group averages. Another possibility that has been used in the GLOBE project, is to present the results to experts of each culture and to adjust the mean if necessary (see, for example, Bertsch, 2012; Minkov \& Blagoev, 2012; Javidan \& House, 2002).

Researchers in international management have to take into account both possible explanations, which always limit the validity of their results. So far, however, these issues have received little scholarly attention. While there is some research that suggests that the differences that exist between the partner firms of IJVs are of importance to the performance of IJVs (see, for example, Barkema \& Vermeulen, 1997, Madhok, 1995), the issues of differences in the perceptions of managers from the different partners have not yet been exhaustively addressed. The few studies that have taken into account the role of perceptual differences have mainly done so in the context of conceptualizing and measuring the performance of IJVs (Geringer and Hebert 1991, Mohr 2006, Zeira, Yeheskel \& Newbury 2004). Differences in the perceptions with regard to other facets of IJVs and IJV management, however, as well as their consequences for IJV performance have so far not been analyzed empirically. This lack of scholarly interest seems surprising, as differences in perception between the partners can be expected to have important consequences for the management of IJVs, due to the high interdependencies of partner firms and the intensive co-operation between managers from the partner firms. The objective of the paper is firstly to explore potential differences that exist in the firm representatives perceptions with regard to a number of key variables. Secondly, to investigate how far the existence of such differences may be related to the performance of an IJV.

Subsequently, the article discusses the potential relationships between the differences in the partners' perceptions and IJV performance and explores these relationships empirically. After outlining the empirical basis and the measures used, the paper presents and discusses the findings. The final section summarizes the main findings and their implications for research and practice. It also discusses the limitations of the study, and points out possible areas for further research.

\section{Differences in the perception of key IJV variables}

As a first step the article investigates the perceptions of German and Chinese managers with regard to a number of variables related to the management of IJVs. These variables have been selected on the basis of a review of extant research on IJV, focusing on areas that have been commonly associated with inter-firm conflicts and/or the performance of IJVs. The analyzed variables are control, complementarity, communication, and the environment of the IJV. In the following, the study discusses in how far the assessments of these four variables by the representatives of IJV partner firms are likely to be similar or different.

\subsection{Control}

Both partners attempt to control the JV activities in order to increase the likelihood that the activities of the JV lead to the achievement of their respective objectives for the IJV (Child \& Yan, 1999, Groot \& Merchant, 2000, Kumar \& Seth, 1998). However, while studies into the consequences of control on JV performance abound, the results remain inconclusive (Guidice \& Cullen, 2007; Awadzi, Kedia, \& Chinat, 1986, Beamish, 1988, Geringer, 1988, Geringer \& Hebert, 1989, Hébert \& Beamish, 1997, Killing, 1983, Kumar \& Esslinger, 1998, Kumar \& Khanna, 2000, Newburry \& Zeira, 1999, Schaan, 1983, West, 1959). Nevertheless, as control can be regarded as crucial for the management of IJVs, it is important for researchers to get a clear picture of the extent of control exerted by each of the partners in order to empirically analyze the existence and strength of the relationship between control and IJV performance. This study uses the term 'control' in the sense of 'influence over the IJV as compared to the partner' rather than 'monitoring' (Pingli, Guliang \& Okano, 2011). Differences in firm representatives' perception of the level of their firm's control over the JV thus refer to differences in the level to which they perceive their side to be able to influence the activities of the JV. A high level of perceived influence on one side should then correspond with low perceived influence by the other side. Therefore, if both partners firms' representatives perceive a similar distribution of control between the partners of the JV, the levels of control perceived by the firms' representatives should be negatively correlated (Chen, Park, \& Newburry, 2009, Li, Zhou \& Zajac, 2009). 


\subsection{Partner complementarity}

Partner complementarity has been recognized as an important prerequisite for the success of IJVs (Brouthers, Brouthers, \& Wilkinson, 1995, Park \& Ungson, 1997). Previous researchers have focused mainly on two types of complementarity, i.e. complementarity of the partner firms' goals and complementarity of the partner firms' resources. Madhok (1995), for instance, argues that complementary partner goals increase the partners' tolerance towards conflicts and unbalanced exchange episodes. Additionally, Abramson \& Ai (1998) suggest that complementary objectives increase the partners' inclination to provide information more openly. Furthermore, firms may be tolerant towards unbalanced exchange episodes despite the existence of hidden agendas on the side of the partner, as long as the partners' goals are assumed to be complementary. These positive outcomes, however, depend require that both partners view their objectives for the IJV as complementary. The second type of complementarity which is seen as important for the success of IJV is the complementarity of partners' resources (Blanchot \& Mayrhofer, 1998, Hill \& Hellriegel, 1994). Complementary resources allow for the achievement of synergies, which are important for the success of the IJV (Park \& Russo, 1996, Parkhe, 1991). For the early stages of an IJV this paper assumes that partner firm representatives have similar perceptions with regard to the complementarity of goals and resources, since without similar perceptions on this issue the IJV would not have been formed. Over time, however, the firms' managers can be expected to acquire more information about the complementarity and their perceptions may start to deviate from one another (Fang \& Zou, 2009). Nevertheless, as this paper expects JVs to terminate if the managers of one side start to view the other side's goals and resources as no longer complementary with their own, there should be some degree of similarity of perceptions in (still) existing JVs.

\subsection{Communication}

Cultural difference obstruct the communication between IJV partners "[P]eople are conditioned by their culture and society as to what to say, when to say it, and how to say it" (Gao, 1996: 281). Various authors have associated different cultures with different types of communication (Shuhui Sophy \& Seeger, 2012, Barker \& Gower, 2010, Chung, 1995, Gudykunst \& Ting-Toomey, 1996, Hall, 1977, Hoon-Halbauer, 1999). Hoon-Halbauer (1999) stressed the importance of other factors that can have a negative impact on the communication and increase the likelihood of misunderstanding between the partner firms' representatives. She subsumes these factors under the heading 'organisational disorder', and mentions factors such as the lack of a clear allocation of responsibilities or too high a number of management levels as examples. These factors are particularly important in IJVs where for each activity there are potentially two partners who assume responsibility. While these factors can be assumed to be of relevance in intra-national JVs as well, it is likely that the inter-cultural dimension increases the complexity, as well as the likelihood of misunderstandings (Jane Zhao \& Anand, 2009). Due to these differences in the way individuals from different cultures communicate, the article assumes that the perceptions of the quality of communication differ between the partner firm representatives (Puck, Rygl \& Kittler, 2007).

\subsection{Environment}

Research in industrial marketing has emphasized the influence of environmental factors on the relationship between firms (Aulakh, Kotabe, \& Sahay, 1996, Ganesan, 1994, Hakansson, 1982). On a more general level theories such as contingency theory (Lawrence \& Lorsch, 1967) or evolution theory (Nelson \& Winter, 1982), for example, have discussed the consequences of a company's maladjustment to its environment (Kraatz, 1998). Differences in managers' perceptions of the environmental threats/opportunities are possible if there is information asymmetry, i.e. if the local managers are better informed about the host country conditions than the foreign partner representatives. Again, as in the case of complementarity this paper suggests that the differences in managers' perceptions of environmental opportunities/threats may change over time. While there may be marked differences at the outset of the IJV relationship, over time partners learn about each other and about the environment, and their perceptions of the environment converge (Chow \& Yau, 2010, Wang \& Fulop 2007).

After examining the potential differences that exist in the firm representatives perceptions with regard to a number of key variables, the next section will investigate in how far the existence of such differences may be related to the performance of an IJV.

\section{Perception asymmetries and performance}

In this section this study analyses the relationship between differences in partner firms' perception and the performance of IJVs. There is little agreement in extant literature as to what constitutes the performance of IJVs and how it should be measured (Nguyen Huu, 2009, Mohr, 2006). The debate revolves around two questions, the first of which relates to the choice of indicators that best reflects the performance of IJVs. Suggestions range from the mere 
existence of the IJV to financial measures, such as the IJV's profitability (Lane, Salk, \& Lyles, 2001). The second question is how these indicators should be measured, i.e. whether 'objective' data (e.g. market share) should be used, or whether managers should (subjectively) evaluate their satisfaction with different indicators (Reus \& Rottig, 2009). For the purpose of this study two constructs are used to tap into the IJV performance perceived by the partner firm representatives. The first construct, labeled short-term performance, includes profitability, growth and market share, while a second construct, named long-term performance, combines the level of technology, stability and competitiveness of the JV. This combination covers short-term as well as long-term performance indicators and reflects indicators that are important to both the German and the Chinese partner firm. The managers' subjective evaluations of the selected performance indicators are used, as will be discussed below.

Overall, it is expected that, with the exception of control, differences in the partner firms' perception of key variables are negatively associated with the performance of the IJV. Regarding the perception of control this paper considers a positive relationship to be more likely for the following reasons. If both partners perceive to have high levels of control, i.e. influence over the IJV activities as compared to the other partner, it is assumed that there are ongoing bargaining processes, and partners compete for influence over the IJV activities (Le, 2009). The article suggests that this competition for influence is detrimental to the IJV performance as it requires resources to be diverted to the coordination of operational policies and to dealing with conflicts. Furthermore, it can be argued that both partners' perception of high levels of influence over the JV may cause some managers of the IJV to experience inter-sender role conflicts (Mohr \& Puck, 2007). This could be expected to negatively affect the performance of the IJV and the perceived performance of the IJV. Overall, the differences in the firm representatives' perception of control over the IJV are positively associated with JV performance (Mjoen \& Tallman, 1997).

Regarding the perception of the other key variables discussed above, a negative association between differences in the perception between firm representatives and the performance of the IJV is more likely. If representatives from the partner firms differ in their perception of goal and resource complementarity in the IJV their commitment to, and willingness to contribute to, the IJV may suffer. The differences in perception are thus likely to be negatively associated with IJV performance.

Communication is a prerequisite for efficiently coordinating organizational processes, in which more than one party is involved (Gemünden, 1999). Difficulties in communication between the firms' representatives thus lead to problems regarding the co-ordination of activities and can have a negative impact on the performance of the IJV. Based on this argument extant literature has stressed the importance of effective communication in IJVs (Hoon-Halbauer, 1999, Schuchardt, 1994). Using case studies, Hoon-Halbauer (1999) has shown the importance of communication between partner firm representatives on the board and the management level. Due to the importance of communication, it is vital that impediments to effective communication are recognized and tackled. This requires, however, that the involved parties do actually perceive such problems. That is, if only one side perceives the communication between the firm representatives to be ineffective, it may be difficult to increase the effectiveness of communication, as the other side may not see the need for doing so. Regarding effective communication to be conducive to the performance of IJVs, differences in firm representatives' perception of communication are likely to be negatively associated with the IJV's performance.

As outlined above, many authors stress the role of environmental factors for the performance of IJVs (Harrigan, 1988, Harrigan, 1985, Kumar \& Seth, 1998, Luo, 1999, Merchant, 2000, Pan \& Tse, 1996, Shan, 1991). As a consequence, IJV managers have to analyze the opportunities/threats of the environment the IJV operates in. It can be assumed that the involved firms' representatives have to be in agreement with regard to the assessment of the environment in order to take action, i.e. to take advantages of environmental opportunities and/or protect themselves against environmental threats. If the firms' representatives have different perceptions as to the existence/magnitude of specific external opportunities and threats, it is unlikely that an initiative or a response to the environmental situation can quickly be agreed on, as the representatives first have to agree on their assessment of the environmental situation. Even if they eventually arrive at a common assessment of the environment, which then can lead to agreement on a course of action for the JV, the time necessary can put the IJV at a disadvantage as compared to faster acting competitors. It thus seems likely that potential differences in firm representatives' perception of environmental factors are negatively associated with the IJV's performance.

\section{Data collection and measures}

The empirical data used to explore the differences in perceptions between JV partners and their relationship with performance was taken from the database one of the authors built on the basis of a large-scale questionnaire survey of German-Chinese Joint Ventures in the winter of 2010/2011. The questionnaire included a range of questions 
geared towards tapping into various aspects of IJV management. As the questionnaire was to be distributed to both representatives of German and representatives of Chinese partner firms, it was first developed in German and then translated into Chinese using the translate/retranslate method suggested by Brislin (1970) and enlisting the help of bilingual research assistants. Through carrying out a pre-test of the instrument among two German and two Chinese researchers and discussing their understanding of the questions, the questionnaire was slightly modified before being sent out. Potential respondents were identified via a database research at the German chambers of foreign trade, the Hoppenstedt-Database, as well as further internet research. This process provided contact details of 392 GCJVs. Questionnaires were sent out to the General Managers of these GCJVs. This led to a return of 110 usable responses. In the letter, General Managers were asked to forward a copy of the questionnaire to a representative of the respective JV partner. 19 of those 110 managers forwarded the questionnaire to their Chinese counterpart. Thus, for 19 GCJVs evaluations were available from both partners $(\mathrm{N}=38)$ and could be used for the statistical analyses. Follow-up calls to managers indicated that a major reason for managers' reluctance to forward the questionnaire to representatives of the partner firm was an unsatisfactory working relationship in general and a lack of communication between the partner firms' representatives in particular. Having only the details of the GM manager for the firms, it was not possible to contact the respective partner firm's representative directly. This led to a comparatively small sample size which was accepted given the exploratory nature of this study.

All variables analyzed in this study were measured using questionnaire items chosen on the basis of existing research on control (Awadzi, Kedia, \& Chinat, 1986, Beamish, 1988, Geringer, 1988, Geringer \& Hebert, 1989, Hébert \& Beamish, 1997, Killing, 1983, Kumar \& Esslinger, 1998, Kumar \& Khanna, 2000, Newburry \& Zeira, 1999, Schaan, 1983, West, 1959), communication (Chung, 1995, Gudykunst \& Ting-Toomey, 1996, Hall, 1977, Hoon-Halbauer, 1999), partner complementarity (Abramson \& Ai, 1998, Madhok, 1995) (Blanchot \& Mayrhofer, 1998, Hill \& Hellriegel, 1994, Park \& Russo, 1996, Parkhe, 1991), the role of the environment (Harrigan, 1988, Harrigan, 1985, Kumar \& Seth, 1998, Luo, 1999, Merchant, 2000, Pan \& Tse, 1996, Shan, 1991) and IJV performance (see, for example, Inkpen \& Birkenshaw, 1994, Mohr, 2006). In order to measure the perception of control, managers were asked to assess the level to which they saw themselves as exerting control over setting the strategic direction of the IJV, over the distribution of profits, and over the staffing of key management positions of the IJV. Two elements were used to measure the complementarity between the partners: complementarity of goals and complementarity of partner resources. In order to assess the perception of the communication between the JV partners, respondents were asked to evaluate intensity, openness, and effectiveness of the communication between the JV partners. The representatives' perception of the IJV's environment was measured by asking managers to evaluate the competitive pressures the IJV faces, the environmental ambiguity, and the extent to which they could rely on the legal system in the PRC. In order to measure IJV performance, respondents were asked to assess the profitability, growth and market share which was combined into a construct called short-term performance (alpha .89) and level of technology, stability and competitiveness of the JV which was combined into a long-term performance construct (alpha .79). In order to explore the link between differences in perception and IJV performance, a measure reflecting the level of symmetry between partner firms' perceptions was needed. To this aim, the absolute value of the result of a subtraction of the Chinese side's evaluation from the German side's evaluation was used. High absolute scores reflect different perceptions, whereas low scores reflect similar perceptions.

\section{Results and Discussion}

\subsection{Differences firm representatives' perceptions}

In order to explore differences in partner firms' perceptions of the selected variables, the partners' perceptions with each other were correlated. Significant positive coefficients imply that firm representatives' perceptions are similar. Significant negative coefficients imply that perceptions of the partner firms' representatives differ.

It is assumed a negative relationship between the levels to which the different partner firm' respondents perceive their side to exert control over the JV. This was based on the argument that high control by one side implies a low level of control by the other side, and vice versa. The correlation coefficients were negative but not statistically significant for the level of control over the strategic direction ( $\mathrm{r}=-0.284$, n.s.), and for the control over profit use $(\mathrm{r}=-0.389$, n.s.). With regard to the degree to which respondents perceive their side to have influence over the staffing of key positions in the JV there was, a strong negative and statistically significant correlation $(\mathrm{r}=-0.519, \mathrm{p}<0.05)$. A possible explanation for the two non-significant coefficients may be the fact that in some IJVs partner firms have focused their control over one or a few specific functional areas. As many German firms contribute advanced production technology to their IJVs in China they are likely to emphasize their influence mainly in the production function (Chung \& Sievert 1995, Mohr 2006). It may also be the case that the association between the perceived 
control and is more complicated as suggested above. For example, it may be the case that respondents were reporting the desired level of control over the respective aspects, rather than the current level of control that their side exerted.

The relationship between the partners' evaluation of complementarity of their goals was positive but not significant $(\mathrm{r}=0.143$; n.s.). This result provides little support for the assumption that partners agree that they have complementary objectives. Similarly, there was no statistically significant relationship between the partners' perceptions of the resource compatibility between them ( $\mathrm{r}=0.395$; n.s.). This result is interesting as far as extant research suggests that complementary objectives and resources are important considerations when selecting a JV partner and also regarded as a requirement for the success of a JV (Blanchot \& Mayrhofer 1998). This result does not suggest that such complementarity does not exist between the firms involved in the IJVs in this sample. Yet, it suggests that a number of partner firm respondents' disagree with regard to the degree to which such complementarity exists in their IJV. This could be due to the fact that some firms did not take into account this aspect when engaging in a JV, or that the degree of complementarity between partner firms has changed over time. For example, the Chinese firm may have acquired knowledge from the German side and may no longer consider the German firms resources as useful. In how far this may play a role for the performance of IJVs will be analyzed below.

This study has suggested that effective communication is vital to the co-ordination of activities between the partner firms. It is assumed that there is a positive association between the partners' perception of communication. The managers' perceptions were positively and significantly associated with one another as regards the effectiveness $(\mathrm{r}=0.481 ; \mathrm{p}<0.5)$ as well as the intensity of the communication $(\mathrm{r}=0.571 ; \mathrm{p}<0.5)$. This means that both sides perceived these facets of communication in a similar way. However, there were no statistically significant relationships with regard to the level to which they perceived the communication to be open ( $r=0.425$; n.s.). This result may be explained by culture-bound notions of what constitutes a misunderstanding and open communication. Anecdotal evidence suggests that Chinese managers may be comparatively more likely to ignore misunderstandings in order to save face (Chung 1995, Gao \& Gudykunst 1996). With regard to the openness of communication, managers from low-context cultures, such as Germany, may consider the lack of explicit information provided by managers from the high-context Chinese cultures as a lack of openness in communication.

In the discussion above it is suggested that there is likely to be a positive association between the firm representatives' perceptions of various facets of the IJV's environment. As expected, their perceptions of the competitive pressures the IJV faces were strongly correlated at a statistically significant level $(\mathrm{r}=0.506 ; \mathrm{p}<0.05)$. Regarding the level to which firm representatives perceive the environment to be ambiguous and the legal system to protect the IJV's activities, there were differences between the perceptions of the German and Chinese managers. None of the correlation coefficients between the managers' perception of these elements was statistically significant (ambiguity $\mathrm{r}=0.241$; n.s.; legal protection $\mathrm{r}=0.043$; n.s.), although both are positive. A possible explanation for the lack of statistically significant correlation regarding the ambiguity may be that in some cases German managers considered the local environment as highly ambiguous (which might have been one of the reasons why they decided to set up a joint venture rather than a wholly owned subsidiary in the first place), whereas the Chinese managers do not consider their 'home' environment to be ambiguous as it is familiar to them. A similar explanation seems plausible for the perception of the legal system.

\subsection{Perception asymmetries and IJV performance}

In order to explore the links between perception asymmetries and IJV performance this article computed a correlation matrix that includes the perception asymmetries of partner firms regarding the 11 variables related to control, complementarity, communication and environment, and the variables reflecting the German and Chinese partner firm representatives' evaluation of IJV performance (see table 1). The last four rows provide the relevant results.

Insert Table 1 here

\subsubsection{Control}

As can be seen from Table 1, there are no significant relationships between the perception asymmetry regarding the partner firms' control over the strategic direction of the JV and re-investment and the performance evaluations of the partner firm representatives. Regarding the perception asymmetry in partner firms' influence over the staffing of key positions, however, there are statistically significant, negative relationships for the short-term and long-term performance assessment by the German side representatives $(-.384, \mathrm{p} \leq .05 ;-.365, \mathrm{p} \leq .05)$. For managers representing a Chinese partner firm, these coefficients are not statistically significant. This means that differences in the 
representatives' perceived influence that their firm has over the staffing of key positions in the IJV coincide with low performance of the IJV. This is contrary to the argumentation above, as it was suggested that the representatives of firms involved in an IJV will evaluate their respective side's influence over the IJV differently and that this asymmetry should be positively associated with the performance of the IJV. While most of the coefficients are not statistically significant, the findings for the role of control over the staffing of key positions in the IJV would imply that for the German firm representatives the opposite relationship exists: perception asymmetries are associated with lower performance. A possible explanation for these findings may be the fact that in successful IJVs both partners try to take credit for the success by claiming control over the IJV's activities.

\subsubsection{Partner Complementarity}

As regards the differences in representatives' perception of the complementarity of the objectives between the partners this paper expected a negative association with IJV performance. As can be seen in Table 1, this negative relationship was only computed for the case of the relationship between perception asymmetry and the German side representatives' assessment of the long-term performance of the IJV $(-.448, \mathrm{p}<.05)$. The other coefficients, though negative, were not statistically significant. For the case of the complementarity of resources, Table 1 shows that none of the coefficients is statistically significant. This means that the perception of complementary resources is not related to the performance of IJVs. A possible explanation for these findings may be that the perception of complementarity of objectives and resources is a necessary, but not sufficient prerequisite for the success of IJV, and other factors are of greater importance.

\subsubsection{Communication}

In order to explore the relationship between the perception asymmetry that exists concerning various aspects of communication and IJV performance this paper calculated the respective correlation coefficients. As can be seen from Table 1, only the coefficient regarding the association between the German side representatives' assessment of the long-term performance and the perception asymmetry regarding the openness of the communication was statistically significant $(-.556, \mathrm{p} \leq .05)$. However, while some of the other coefficients were negative in line with the argumentation above, none of them was statistically significant. This finding may be due to the fact that the asymmetry that was found to exist with regard to most of the facets of communication is a consequence of the representatives' cultural background. Partner firm managers may have learned to deal with these culture-bound differences in communication behavior and they therefore do not affect the performance of the IJV.

\subsubsection{Environment}

The results for the relationships between the asymmetry in representatives' perception of environmental factors and IJV performance show that the differences in particular their perceptions of competitive pressures are of importance. The extent of these differences is negatively related to both the German and the Chinese side representatives' assessment of the short and long-term performance of the IJV on statistically significant levels. None of the other coefficients was statistically significant. Thus, differences in the perception of the degree of ambiguity and the legal protection of the business activities of the IJV do not seem to be relevant for the performance of the IJVs. While the empirical results are not entirely in line with this papers argumentation, these results seem to be of major interest. Competitive pressure may have a more direct and immediate impact on the performance of IJVs than most other facets of the environment. Different perceptions of the degree of competitive pressures the IJV is exposed to are likely to result in differences in partner firms' preferred course of action for the IJV. This explanation is also supported by the strong and statistically significant association between the perception asymmetries that exist regarding the competitive pressures and the complementarity of objectives $(.654, \mathrm{p} \leq .01$, see Table 1$)$

\section{Conclusion}

This study has empirically analyzed the degree to which partner representatives' perceptions of various aspects of IJV management differ. While not all of the coefficients were statistically significant, the findings show that firm representatives have largely similar perceptions of the level of complementarity, the nature of communication between partner firms, and the environment of the IJV. With regard to the level to which representatives' viewed their side as exerting control, there were negative correlations in line with the argumentation above, i.e. there seems to be agreement about the distribution of control between the partners. The existence of differences in partner firm representatives' perceptions is relevant for companies engaged in IJVs in a number of ways. Existing differences in perceptions can lead to differences in the actions that partner firms require on IJV level, leading to conflicts. Differences in perceptions can also prevent the efficient implementation of agreements, if these are based on different assessments of, for example, the degree to which the IJV is faced with competitive pressures. The existence 
of differences in the perceptions of partner firm representatives has also consequences for (empirical) research into IJVs. Studies that rely on subjective assessment of respondents from only one of the partner firms have to be aware that this information is likely to be different than the assessments that would have been provided by managers representing the other side of the IJVs.

In a second step this article empirically investigated the relationship between the extent of differences in representatives' perceptions and their evaluation of the performance of their IJV. Although not all of the coefficients were statistically significant, most correlations between the perception asymmetry and IJV performance measures were negative. The results show particularly strong relationships between the asymmetries in partner firm representatives' perception of the magnitude of competitive pressures and their evaluation of IJV performance. High levels of asymmetries correspond with low levels of performance for both the Chinese and the German side representatives. While the evidence is not as clear-cut for other variables, this study suggests that the findings provide some insights into an important issue that has not yet been exhaustively investigated. From a practical point of view, these results show that some of the perception asymmetries that were shown to exist are associated with the assessment of an IJV's performance. Perception asymmetries may be an indicator for the existence of more fundamental problems of the JV relationship, such as a lack of exchange of information, which in turn may be caused by a lack of trust between the partners. In addition, it may be possible that differences in the perceptions of partner firm representatives follow from differences in the assessment of performance. Partner firms may have different explanations for the weak or strong performance of an IJV (Brunetto \& Farr-Wharton 2007). Future research should account for the differences in firm representatives when empirically studying IJVs. The findings also highlight differences between German and Chinese side representatives. For example, while the perception asymmetry with regard to the staffing of key positions in the IJVs was negatively associated with the performance assessment of German side representatives, no such association existed for the Chinese side. While this may have little to do with cultural differences, it highlights the importance of personal control for foreign firms in their JVs in the PRC.

There are a number of limitations that have to be considered. First, the empirical basis was limited to a small number of GCJVs. This can be seen as limiting the generalizability of the findings. However, the primary research objective was to explore differences in partner firms' perception of key variables in IJV management, rather than identifying generalizable relationships. Future research should try to analyze differences in partner firms' perceptions using larger samples, and/or analyze IJVs with partners from other cultures. The analysis could also be extended to include other types of strategic alliances. A second limitation is the fact that the sample was biased towards successful firms with a good relationship between the partner firms, as representatives from both partner firms filled in the questionnaire. It can be assumed only one side's responses would be received from GCJVs where the relationship between partner firms is difficult. A final limitation that needs to be taken into account when interpreting the results of this study, relates to the difficulty of measuring perceptions of managers. As outlined above, individual perceptions influence individual action in IJVs and should thus be taken into account; more work is needed to arrive at better ways to empirically measure perceptions and also to investigate the correspondence between perceptual and factual measures. In particular, better ways are needed to assess perceptual differences, as the computation of difference scores, as used in the study, is associated with a number of problems. This study suggests that in addition to the subjective/objective distinction, researchers should also take into account differences in the subjective assessment, in particular when investigating perceptions of the same issue by individuals from different companies/cultural backgrounds. The performance measures used in this study were developed on the basis of the interviews with German and Chinese managers by Mohr (2006) and included indicators that were important to both the German and Chinese IJV partners. On a general level, the results of the study - while underlining the existence of differences in perceptions - provide further evidence of the problems associated with quantitative studies in the field of international management. Perceptions may not be amenable to measurement through questionnaire surveys and may require other ways of assessment instead.

\section{References}

Abramson, N. R., \& Ai, J. X. (1998). Practising Relationship Marketing in Southeast Asia. Reducing Uncertainty and Improving Performance. Management International Review. 1998/1. 113-43.

Ahmed, M. M., Chung K. Y., \& Eichensehe J. W. (2003). Business Students' Perceptions of Ethics and Moral

Judgement: A Cross-Cultural Study. Journal of Business Ethics. 43(1/2). 89-103. http://dx.doi.org/10.1023/A:1022915316112 
Aulakh, P. S., Kotabe M., \& Sahay A. (1996). Trust and Performance in Cross-Border Marketing Partnerships. A Behavioral Approach. Journal of International Business Studies. 27(5). 1005-32. http://dx.doi.org/10.1057/palgrave.jibs.8490161

Awadzi, W., Kedia, B. L., \& Chinat, R. (1986). Performance implication of locus of control and complementary resources in international joint ventures. Paper presented at Presented at the Academy of International Business Conference, London.

Barkema, H. G., \& Vermeulen, F. (1997). What differences in the cultural backgrounds of partners are detrimental for international joint ventures? Journal of International Business Studies. 28(4). 845-64. http://dx.doi.org/10.1057/palgrave.jibs.8490122

Barker, R., \& Gower, K. (2010). Strategic Application of Storytelling in Organizations: Toward Effective Communication in a Diverse World. Journal of Business Communication. 47(3). 295-312. http://dx.doi.org/10.1177/0021943610369782

Beamish, P. W. (1988). Multinational Joint Ventures in Developing Countries. London, New York: Routledge.

Bertsch, A. M. (2012). Validating GLOBE's Societal Values Scales: A Test in the U.S.A. International Journal of Business \& Social Science. 3(8). 10-23.

Blanchot, F. \& Mayrhofer, U. (1998). Empirical Literature on Joint Venture Success. A Review of Performance Measures and of Factors Affecting Longevity: Cahier du Cesag, IECS Strasbourg, Université Robert Schuman.

Brislin, R. W. (1970). Back-Translation for Cross-Cultural Research. Journal of Cross-Cultural Psychology. 1. 185-215. http://dx.doi.org/10.1177/135910457000100301

Brouthers, K. D., Brouthers, L. E., \& Wilkinson, T. J. (1995). Strategic Alliances: Choose Your Partners. Long Range Planning. 28(3). 18-25. http://dx.doi.org/10.1016/0024-6301(95)00008-7

Brunetto, Y., \& Farr-Wharton, R. (2007). The Moderating Role of Trust in SME Owner/Managers' Decision-Making about Collaboration. Journal Of Small Business Management, 45(3), 362-387. http://dx.doi.org/10.1111/j.1540-627X.2007.00218.x

Burrell, G., \& Morgan G. (1985). Sociological Paradigms and organisational analysis. Hants: Gower.

Chen, D., Park, S., \& Newburry, W. (2009). Parent contribution and organizational control in international joint ventures. Strategic Management Journal, 30(11), 1133-1156. http://dx.doi.org/10.1002/smj.784

Child, J., \& Yan, Y. (1999). Investment and Control in International Joint Ventures. The case of China. Journal of World Business. 34(1). 3-15. http://dx.doi.org/10.1016/S1090-9516(99)00003-6

Chung, T. Z. (1995). Interkulturelle Kommunikation und Joint Venture Management in China. In T. Z. Chung, \& H.-W. Sievert (Eds.). Joint Ventures im chinesischen Kulturkreis. Wiesbaden: Gabler. http://dx.doi.org/10.1007/978-3-322-82650-3_6

Chung, T. Z., \& Sievert, H.-W. (1995). Joint Ventures im chinesischen Kulturkreis. Wiesbaden: Gabler.

Chow, R. M., \& Yau, O. M. (2010). Harmony and cooperation: their effects on IJV performance in China. Cross Cultural Management, 17(3), 312-326. http://dx.doi.org/10.1108/13527601011068397

Elahee, M. N., Kirby S. L., \& Nasif E. (2002). National culture, trust, and perceptions about ethical behavior in intraand cross-cultural negotiations: An analysis of NAFTA countries. Thunderbird International Business Review. 44(6). 799-819. http://dx.doi.org/10.1002/tie.10049

Fang, E., \& Zou, S. (2009). Antecedents and consequences of marketing dynamic capabilities in international joint ventures. Journal Of International Business Studies, 40(5), 742-761. http://dx.doi.org/10.1057/jibs.2008.96

Ganesan, S. (1994). Determinants of Long-Term Orientation in Buyer-Seller Relationships. Journal of Marketing. 58(April). 1-19. http://dx.doi.org/10.2307/1252265

Gao, G., Ting-Toomey, S., \& Gudykunst, W. B. (1996). Chinese Communication Processes. In M. H. Bond (Ed.). The Handbook of Chinese Psychology. Oxford: Oxford University Press.

Gemünden, H. G. (1999). Management of Relationships. The Importance of Intangible Factors. In S. Urban (Ed.). Relations of Complex Organizational Systems. Wiesbaden: Gabler.

Geringer, J. M. (1988). Joint Venture partner selection: strategies for developed countries. New York. London: Quorum. 
Geringer, J. M., \& Hebert L. (1989). Control and Performance of International Joint Ventures. Journal of International Business Studies. 20(2). 235-54. http://dx.doi.org/10.1057/palgrave.jibs.8490359

Geringer, J. M., \& Hebert, L. (1991). Measuring Performance of International Joint Ventures. Journal of International Business Studies. 22(2). 249-63. http://dx.doi.org/10.1057/palgrave.jibs.8490302

Groot, T. L. C. M., \& Merchant, K. A. (2000). Control of international joint ventures. Accounting, Organization and Society. 25(6). 579-607. http://dx.doi.org/10.1016/S0361-3682(99)00057-4

Gudykunst, W. B., \& Ting-Toomey, S. (1996). Culture and Interpersonal Communication. Beverly Hills, CA.

Guidice, R. M., \& Cullen, J. B. (2007). A Strong Inference Test of the Effects of Strategic Interdependence on the JV Control-Performance Relationship. Journal of Business \& Management. 13(2). 127-153.

Hakansson, H. (Ed.) (1982). International Marketing and Purchasing of Industrial Goods. Chichester: John Wiley and Son.

Hall, E. T. (1977). Beyond Culture. Garden City, NY.

Harrigan, K. R. (1988). Joint Ventures and Competitive Strategy. Strategic Management Journal. 9(2). 141-58. http://dx.doi.org/10.1002/smj.4250090205

Harrigan, K. R. (1985). Strategies for Joint Ventures. Lexington, Mass.: Lexington Books.

Hébert, L., \& Beamish, P. (1997). Characteristics of Canada-Based International Joint Ventures. In P. W. Beamish, \& J. P. Killing (Eds.). Cooperative Strategies. North American Perspectives. San Francisco: The New Lexington Press.

Hill, R., \& Hellriegel, D. (1994). Critical Contingencies in joint venture management. Some lessons from managers. Organization Science. 5(4). 594-607. http://dx.doi.org/10.1287/orsc.5.4.594

Hoon-Halbauer, S. K. (1999). Managing Relationships Within Sino-Foreign Joint Ventures. Journal of World Business. 34(4). 344-71. http://dx.doi.org/10.1016/S1090-9516(99)00023-1

Inkpen, A. C., \& Birkenshaw, J. (1994). International Joint Ventures and Performance: an Interorganizational Perspective. International Business Review. 3(3). 201-17. http://dx.doi.org/10.1016/0969-5931(94)90002-7

Jane Zhao, Z., \& Anand, J. (2009). A multilevel perspective on knowledge transfer: evidence from the Chinese automotive industry. Strategic Management Journal, 30(9), 959-983. http://dx.doi.org/10.1002/smj.780

Javidan, M. \& House, R. (2002). Leadership and cultures around the world: findings from GLOBE. Journal of World Business. 37(1). 1-2. http://dx.doi.org/10.1016/S1090-9516(01)00068-2

Killing, J. P. (1983). Strategies for Joint Venture Success. London/ Canberra: Croom Helm.

Kraatz, M. S. (1998). Learning by Association? Interorganizational Networks and Adjustment to Environmental Change. Academy of Management Journal. 41(6). 621-43. http://dx.doi.org/10.2307/256961

Kumar, B. N., \& Esslinger, S. (1998). Coorporate Management in German Companies in East Asia. Similarities and Differences in Parent-Company Control in Japanese and Chinese subsidiaries. In Y. Takahashi, M. Murata, \& K. M. Rahman (Eds.). Management Strategies of Multinational Corporations in Asian Markets. Tokyo: Chuo University Press.

Kittler, M.G., Rygl, D. \& Mackinnon, A. (2011). Special Review Article: Beyond culture or beyond control? Reviewing the use of Hall's high-/low-context concept. International Journal of Cross Cultural Management, 11(1). 63-82. http://dx.doi.org/10.1177/1470595811398797

Kumar, B. N., \& Khanna, M. (2000). Increasing Competitiveness of Indo-German Joint Ventures: The Role of Joint Venture Autonomy for Success. In F.-J. Richter (Ed.). The Asian Economic Catharsis. Westport, Conn. London: Quorum.

Kumar, S., \& Seth, A. (1998). The design of coordination and control mechanisms for managing joint venture-parent $\begin{array}{lllll}\text { relationships. } & \text { Strategic } & \text { Management } & \text { Journal, } & \text { 19(6). }\end{array}$ http://dx.doi.org/10.1002/(SICI)1097-0266(199806)19:6<579::AID-SMJ959>3.0.CO;2-8

Lane, P. J., Salk, J. E., \& Lyles, M. A. (2001). Absorptive Capacity, Learning, and Performance in International Joint Ventures. Strategic Management Journal, 22(12). 1139-1161. http://dx.doi.org/10.1002/smj.206

Lawrence, P. R., \& Lorsch, J. W. (1967). Organization and environment. Managing differentiation and integration. Boston: Harvard Business School Press. 
Le, N. H. (2009). Do Partners' Differences Affect International Joint Venture Control and Performance? Journal Of International Business Research. 8(2). 67-86.

Li, J., Zhou, C., \& Zajac, E. J. (2009). Control, collaboration, and productivity in international joint ventures: theory and evidence. Strategic Management Journal, 30(8), 865-884. http://dx.doi.org/10.1002/smj.771

Luo, Y., \& Tan, J. J. (1999). International Joint Ventures in China. In L. Kelley, \& Y. Luo (Eds.). China 2000. Emerging Business Issues. Thousand Oaks, CA: Sage.

Madhok, A. (1995). Revisiting multinational firms' tolerance for joint ventures. Journal of International Business Studies, 26(1). 117-38. http://dx.doi.org/10.1057/palgrave.jibs. 8490168

Merchant, H. (2000). Configurations of International Joint Ventures. Management International Review. 40(2). $107-40$

Minkov, M., \& Blagoev, V. (2012). What do Project GLOBE's cultural dimensions reflect? An empirical perspective. Asia Pacific Business Review, 18(1). 27-43. http://dx.doi.org/10.1080/13602381.2010.496292

Mjoen, H., \& Tallman, S. (1997). Control and Performance in International Joint Ventures. Organization Science. 8(3). 257-274. http://dx.doi.org/10.1287/orsc.8.3.257

Mohr, A. T. (2006). A multiple constituency approach to IJV performance measurement. Journal of World Business. 41. 247-60. http://dx.doi.org/10.1016/j.jwb.2006.06.002

Mohr, A. T., \& Puck, J. F. (2007). Role Conflict, General Manager Job Satisfaction and Stress and the Performance of IJVs. European Management Journal. 25(1). 25-35. http://dx.doi.org/10.1016/j.emj.2006.11.003

Nelson, R. R., \& Winter, S. G. (1982). An evolutionary theory of economic change. Cambridge: Belknap Press.

Newburry, W., \& Zeira, Y. (1999). Autonomy and Effectiveness of Equity International Joint Ventures (EIJV's). Journal of Management Studies. 36(2). 263-85. http://dx.doi.org/10.1111/1467-6486.00136

Nguyen Huu, L. (2009). Foreign Parent Firm Contributions, Experiences, and International Joint Venture Control and Performance. International Management Review. 5(1). 56-69.

Owen, C. L., \& Scherer, R. F. (2002). Doing business in Latin America: Managing cultural differences in perceptions of female expatriates. S.A.M. Advanced Management Journal. 67(2). 37.

Pan, Y., \& Tse, D. K. (1996). Cooperative Strategies between Foreign Firms in an Overseas Country. Journal of International Business Studies. 27(5). 929-46. http://dx.doi.org/10.1057/palgrave.jibs.8490157

Park, S. H., \& Russo, M. V. (1996). When Competition Eclipses Cooperation. An Event History Analysis of Joint Venture Failure. Management Science. 42. 875-90. http://dx.doi.org/10.1287/mnsc.42.6.875

Park, S. H., \& Ungson, G. R. (1997). The Effect of National Culture, Organizational Complementarity, and Economic Motivation on Joint Venture Dissolution. Academy of Management Journal. 40(2). 279-307. http://dx.doi.org/10.2307/256884

Parkhe, A. (1991). Interfirm diversity, organizational learning, and longevity in global strategic alliances. Journal of International Business Studies. 22(4). 579-601. http://dx.doi.org/10.1057/palgrave.jibs.8490315

Pingli, L., Guliang, T., \& Okano, H. (2011). The control of international joint ventures involving Chinese partners. Financial Management (14719185), 54-55.

Puck, J.F., Rygl, D., \& Kittler, M.G. (2007). Cultural antecedents and performance consequences of open communication and knowledge transfer in multicultural process-innovation teams. Organisational Transformation and Social Change, 3(2). 223-241. http://dx.doi.org/10.1386/jots.3.2.223_1

Reus, T. H., \& Rottig, D. (2009). Meta-analyses of International Joint Venture Performance Determinants. Management International Review (MIR). 49(5). 607-640. http://dx.doi.org/10.1007/s11575-009-0009-4

Romaniuk, J., \& Sharp, B. (2003). Measuring Brand Perceptions: Testing Quantity and Quality. Journal of Targeting, Measurement and Analysis for Marketing. 11(3). 218-30. http://dx.doi.org/10.1057/palgrave.jt.5740079

Schaan, J. L. (1983). Parent control and joint venture success: The case of Mexico., PhD. Dissertation. University of Western Ontario.

Schuchardt, C. A. (1994). Deutsch-chinesische Joint-ventures. München/Wien: Oldenbourg Verlag. 
Shan, W. (1991). Environmental Risks and Joint Venture Sharing Arrangements. Journal of International Business Studies. 4. 555-78. http://dx.doi.org/10.1057/palgrave.jibs.8490314

Shuhui Sophy, C., \& Seeger, M. W. (2012). Cultural Differences and Communication Issues in International Mergers and Acquisitions: A Case Study of BenQ Debacle. International Journal of Business \& Social Science. 3(3). 116-127.

Triandis, H. C. (1982). Dimensions of Cultural Variation as Parameters of Organizational Theories. International Studies of Management and Organization. 12(4). 139.

Wang, K., \& Fulop, L. (2007). Managerial trust and work values within the context of international joint ventures in China. Journal Of International Management, 13(2), 164-186. http://dx.doi.org/10.1016/j.intman.2006.11.001

Weber, E. U. \& Hsee, C. (1998). Cross-cultural Differences in Risk Perception, but Cross-cultural Similarities in Attitudes. Management Science. 44(9). 1205-18. http://dx.doi.org/10.1287/mnsc.44.9.1205

West, M. W. (1959). Thinking ahead. The jointly owned subsidiary. Harvard Business Review. 37. 165-72.

Wilson, M., Chen, S., \& Erakovic, L. (2006). Dynamics of decision power in the localization process: comparative case studies of China-Western IJVs. International Journal Of Human Resource Management, 17(9), 1547-1571. http://dx.doi.org/10.1080/09585190600878352

Zeira, Y., Yeheskel, O., \& Newbury, W. (2004). A comparative analysis of performance assessment: International joint venture managers versus regional headquarters managers. The International Journal of Human Resource Management. 15(4,5). 670-87. 
Table 1. Correlation Matrix: Level of asymmetry in partners' perceptions representatives' perception of performance

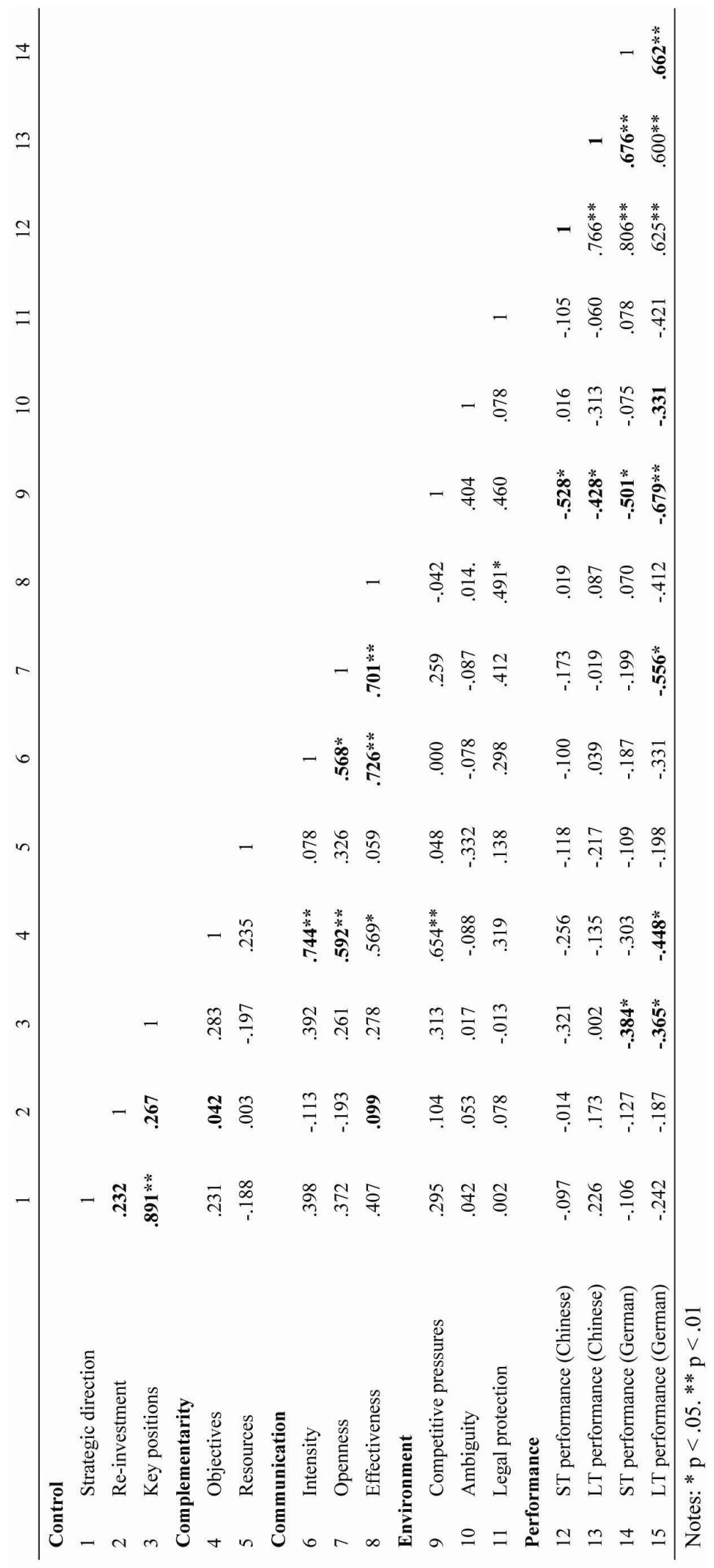

